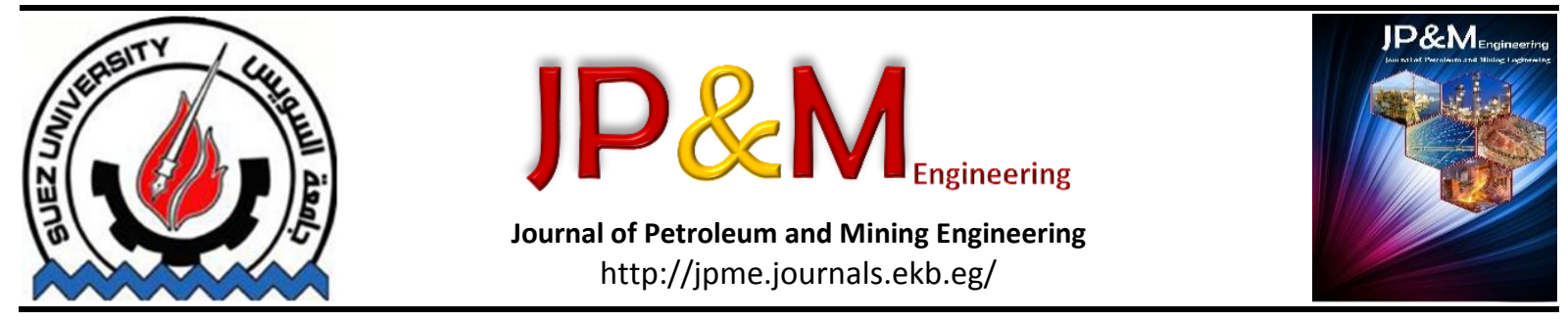

\title{
Influence of Designe Parameters Change on Mass Transfer and Productivity in A Tubular Solar Still
}

\author{
Abdelhady M. Zaghloul \\ Friedrichshafen, Baden-Württemberg, Germany
}

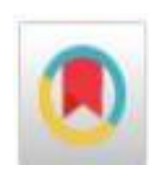

\begin{abstract}
In this work, investigation of the main parameters affecting solar still performance under the weather conditions of the Suez-Gulf area is considered. Three solar still units are designed and constructed with different radii to operate under the same weather conditions with different design parameters. With one fullTSS model and two half-TSS models, three experiments were conducted to study how to obtain the maximum productivity during the day. In every efficient solar still design, water temperature, vapor temperature and distillate output, and difference between water temperature and inner glass cover temperatures are very important. The purpose of this research is to design a water distillation system that can purify water from nearly any source, a system that is relatively cheap, portable, and depends only on renewable solar energy. From the results of project calculations a truthful estimate was made to prototype the most effective geometries of the distiller and trough concentration system, one that will maximize evaporation/condensation and recapture waste heat to minimize thermal losses. Future goals for this project include calculation refinement, material research/testing, and fabrication. The test took place in Suez-Bay (latitude of $29^{\circ}$ $966^{\prime}$ and longitude of $\left.32^{\circ} 549^{\prime}\right)$.
\end{abstract}

\section{Introduction}

Distillation has historically been the main method for separating the component substances from a liquid mixture by selective evaporation and condensation. Several technologies have been used for about a century in land-based plants and on ships to provide water for a crew. In principle, the water from a solar still should be quite pure. The slow distillation process allows only pure water to evaporate from the basin and collect on the cover, leaving all particulate contaminants behind. A historical review may help to understand the main concept of desalination procuresses through last centuries.

Scarcity may be a social construct (a product of affluence, expectations and customary behavior) or the consequence of altered supply patterns-stemming from climate change for example [1]. Desalination systems using traditional fuels have been used in many countries in the Middle and Near East to produce fresh water. It is interesting to note that many of these countries where desalination has been used extensively are characterized by a high intensity of incident solar energy [2]. Water is considered one of the prime elements responsible for life on earth. It covers three-fourths of the surface of the earth.
However, over most of earth's water is found in oceans as salt water, contains too much of salt, cannot be used for drinking, growing crops or most industrial uses. [3]. The performance of solar distillation systems depends on climatic parameters such as ambient temperature, solar radiation intensity and weather condition etc., design parameters like inclination angle and operational parameters like orientation of solar still and brine water depth [4]. It has been found that with the increment in solar radiation intensity [5] and ambient temperature, the productivity of the solar still increases $[5,6]$.

\section{Materials and Methods}

\section{Experimental Set Up}

With one full-TSS model and two half-TSS models, three experiments were conducted in the same location as presented in Suez, Egypt $\left(29.966^{\circ} \mathrm{N}, 32.549^{\circ} \mathrm{E}\right)$ with the same weather conditions to study how to obtain the maximum productivity during the day. The first experiment took place in 2014, May $14^{\text {th }}$ with the full tube model of TSS and different diameters $200 \mathrm{~mm}, 300 \mathrm{~mm}$ and $400 \mathrm{~mm}$. In 2015, June $2^{\text {nd }}$ another experiment was conducted with half-TSS with the constant tray dimensions $1200 \mathrm{~mm}, 150 \mathrm{~mm}$ and $30 \mathrm{~mm}$. Figure (1) shows the experimental set up of the full TSS. Figure (2) 
displays the second experiment model which was designed as half-tubular still with different Radii $100 \mathrm{~mm}$, $150 \mathrm{~mm}$ and $200 \mathrm{~mm}$ and constant tray dimensions $1200 \mathrm{x}$ $150 \times 30 \mathrm{~mm}$. The last experiment model was designed as half-tubular stills with variable tray widths of 200, 300 and $400 \mathrm{~mm}$ as shown in figure (3). All models consist of basin liner which absorbs incident solar radiations that are transmitted through the tubular glass cover. Basin liner is made of a galvanized steel sheet of $1 \mathrm{~mm}$ thickness and coated with black paint for better solar absorption. It has an area of $1.2 \mathrm{~m} \times 0.15 \mathrm{~m}$. No heat losses occurred from the bottom and side walls of solar still as it is all enclosed into the tubular solar still. The condensing cover of solar still is made of highly transparent plastic of $3 \mathrm{~mm}$ thickness and is placed on vertical walls of the distillate channel of the solar still. The condensed water gets collected in a distillate channel. A plastic pipe is connected to the distillate channel to drain distillate water to a scaled measuring jar and a drainage pipe is connected to remove wastes inside the solar still. Rubber gaskets are provided between glass cover and vertical walls to prevent heat loss. Thermocouples shown in the schematic figure (2) are fixed into the solar still to measure the basin liner, as well as glass and water temperatures. The thermocouple fixed outside the basin measures the outside temperature of the basin. These thermocouples are connected to digital temperature indicators to indicate the hourly temperature readings. Figure (4) illustrates the fixed and the variable dimensions trays. Three empty bottles with size about 1.5 liter, three equal pieces of hose, each is about 1 meter in length, three pails to receive distilled water, three thermocouple wires in each tube and thermocouple device to determine temperatures. Sheets of plastic used to close the ends of each tube, silicon film is applied using silicon gun to fasten the plastic sheets and to prevent heat loss.

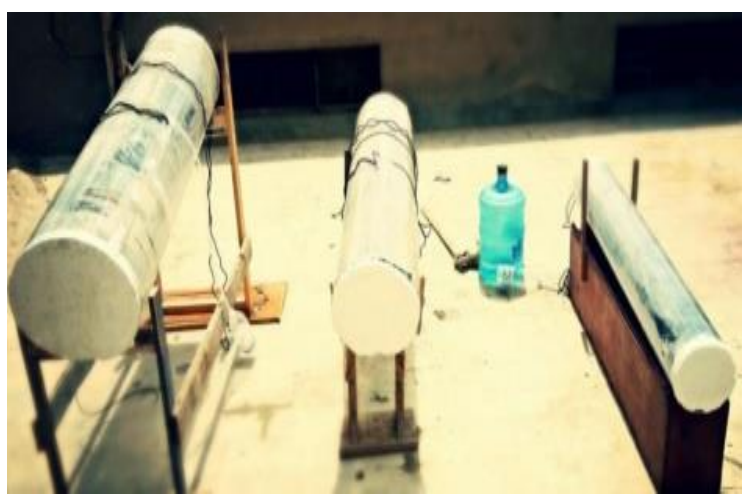

Figure 1Experimental set-up of the full-TSS model with constant tray dimensions

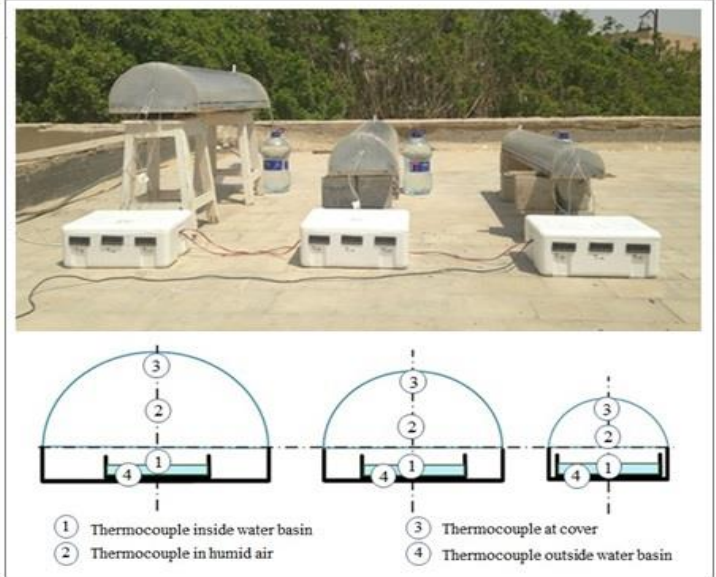

Figure 2Experimental set-up of the half-TSS model with constant tray dimensions and thermocouples position

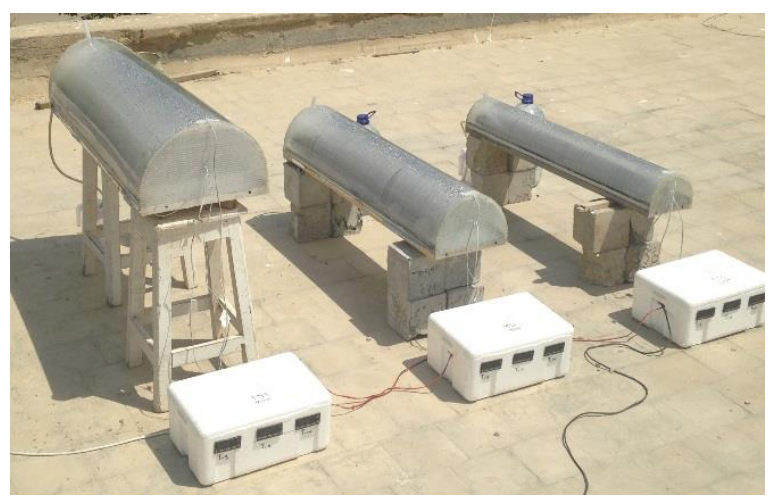

Figure 3 Experimental set-up of the half-TSS model with variable tray dimensions

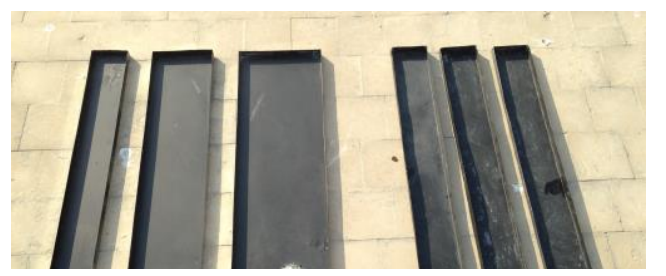

Fig. 4 Constant and variable dimensions trays

\section{Methodology of solar distillation}

The mechanism of solar distillation is as follows:

a) The sun energy in the form of short electromagnetic waves passes through the transparent/opaque condensing cover (Glass/plastic/copper) and strikes at the blacked bottom surface of the still. This light changes its wavelength to long wave of heat, which is added to the water kept in the sallow basin bellow the cover.

b) The water heats up it starts evaporating.

c) These warm vapors start rising upwards towards the inner surface of the cooler cover plate. There these get condensed releasing their latent heat of condensation and 
forming a sheet of water on the under surface of the transparent cover.

d) This condensed water than slips down the inner surface of the cover plate toward the distillate trough due to gravity.

\section{Results}

Some comparisons were made between weather conditions and other parameters that affect the half tubular solar still to study the model efficiency. All comparisons took place during the day time from 09:00 am to $06: 00 \mathrm{pm}$ to study the hourly variation between the different parameters. It was important to conduct all tests in the same weather conditions to differentiate between the models performances. Solar intensity, ambient temperature and wind speed measurements were taken on days 14/05/2014, $02 / 06 / 2015$ and 08/06/2015 and compared to each other as shown in figures (5), (6) and (7). The line graph in figure (8) shows an hourly influence of solar intensity on water temperature. The main trend in the figure shows a relatively high solar intensity from 10:00 am to 02:00 pm. A significant drop of solar intensity noticed from $596 \mathrm{~W} / \mathrm{m}^{2}$ to $45 \mathrm{~W} / \mathrm{m}^{2}$ due to sunset from 03:00 pm to 06:00 pm. The graph points out the maximum solar intensity of $724 \mathrm{~W} / \mathrm{m}^{2}$ captured from the sun at $12: 00 \mathrm{pm}$ with the maximum water temperature of $61.4^{\circ} \mathrm{C}$ at the same time. Water temperature gives a fluctuated increase from $40.7^{\circ} \mathrm{C}$ at $09: 00$ am to $60.1^{\circ} \mathrm{C}$ at $02: 00 \mathrm{pm}$, followed by a slight decrease in water temperature from $55.3^{\circ} \mathrm{C}$ to $41.8^{\circ} \mathrm{C}$ from $03: 00 \mathrm{pm}$ towards the end of the time frame at 06:00 pm.

Water temperature is compared to ambient temperature in figure (9) where the graph shows a steady increase of ambient temperature at the beginning of the day to the mid-day when it achieves the maximum in ambient temperature and water temperature at $12: 00 \mathrm{pm}$ with $48.6^{\circ} \mathrm{C}$ and $61.4^{\circ} \mathrm{C}$ respectively. The water temperature nearly keeps constant from 12:00 pm to 02:00 pm when the ambient temperature gradually decreases from 12:00 $\mathrm{pm}$ to the next four hours to reach $49.2^{\circ} \mathrm{C}$, followed by a temperature fluctuation at the end of the day.

The effect of wind speed was taken into account while studying the performance of the half tubular solar still. There is an inverse relationship between the speed of wind and the temperature. A high wind speed cools down the temperature of the solar still. Another comparison was drawn between the wind speed and the glass cover temperature, as the temperature of the cover plays a basic role in the evaporation-condensation process. When the vapor temperature is considerably higher than the condensing cover temperature, the condensation rate is higher accordingly. As plotted in the line graph in figure (10) below, it is clear that the wind speed is proportionally low with some fluctuations from 09:00 am to $05: 00 \mathrm{pm}$ with maximum value of $2.8 \mathrm{~m} / \mathrm{s}$ at 01:00 pm and 04:00 pm with no clear effect on the cover temperature. At 06:00 pm the wind reaches its ultimate value of about $5 \mathrm{~m} / \mathrm{s}$ with a modest decrease from $42^{\circ} \mathrm{C}$ to $37^{\circ} \mathrm{C}$ in glass cover temperature.

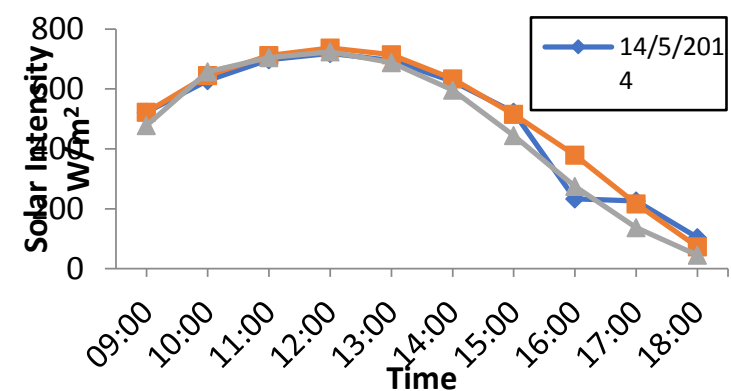

Figure 5Solar intensity variation through the three days

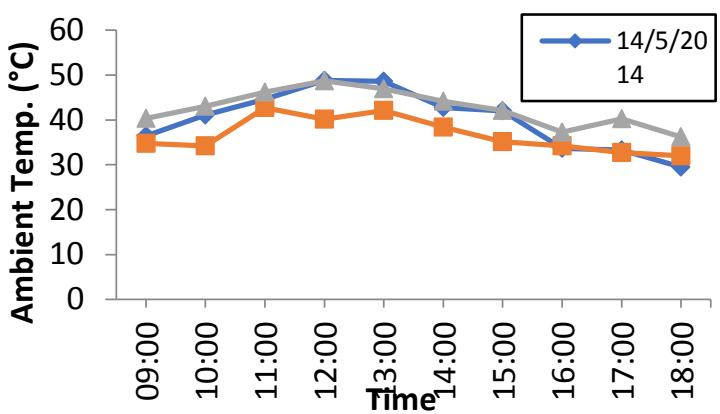

Figure 6 Ambient temperature variation through the three days

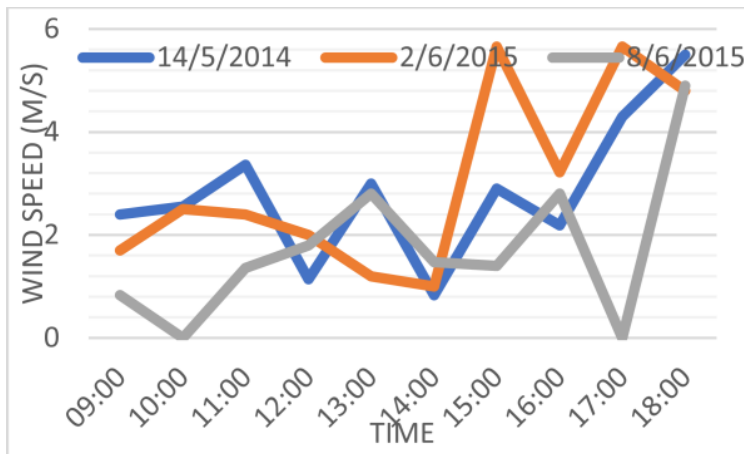

Fig. 7 Wind speed variation through the three days

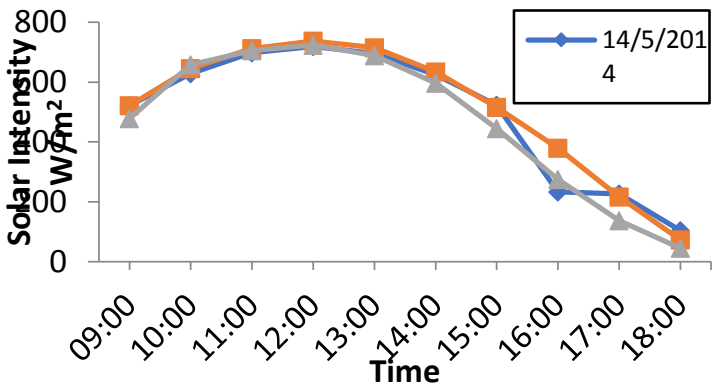

Figure 8 Influence of the solar intensity on the water temperature 


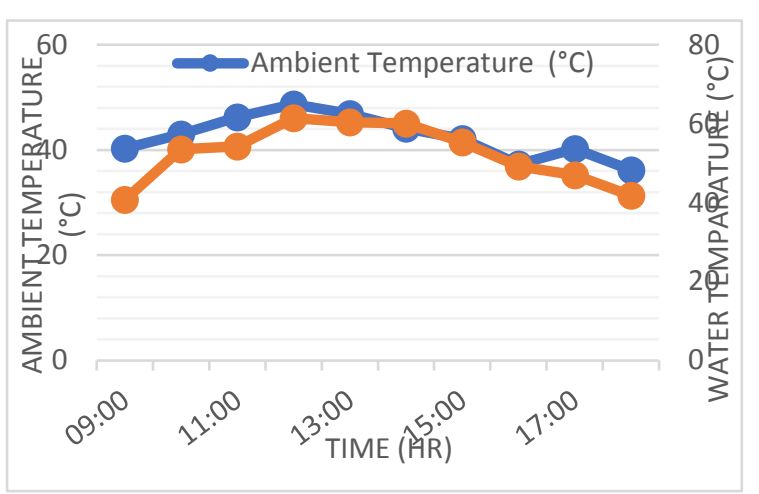

Figure 9Influence of the ambient temperature on the water temperature

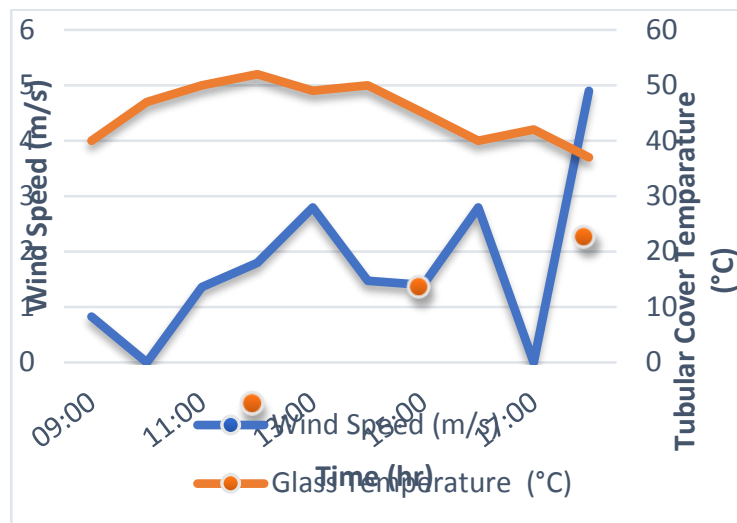

Figure 10 Influence of the wind speed on the glass temperature

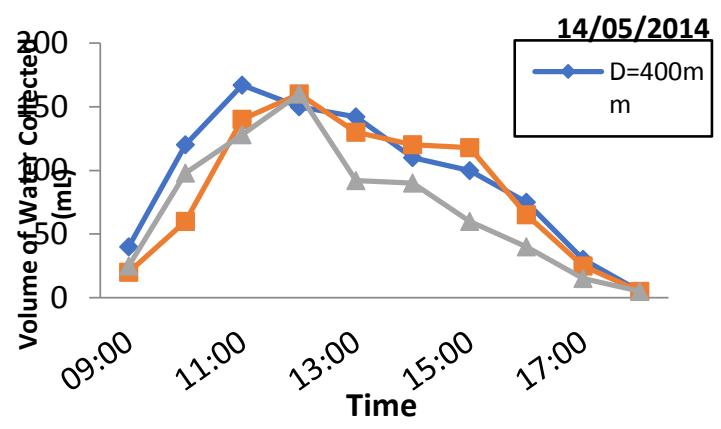

Figure 11 The hourly amount of water distilled from the full-TSS models

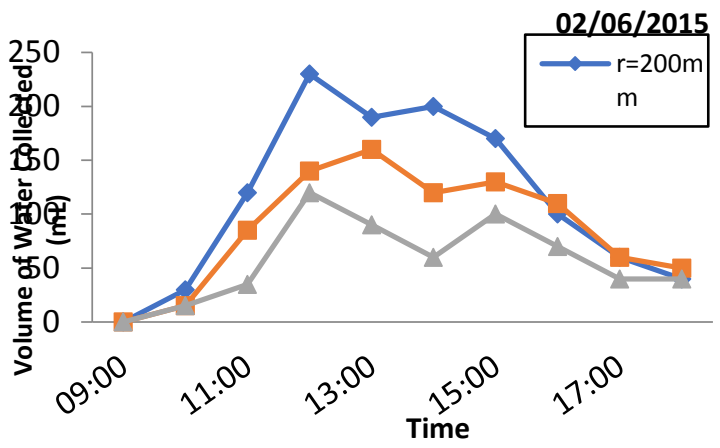

Figure 12The hourly amount of water distilled from the half-TSS models with variable tray dimensions

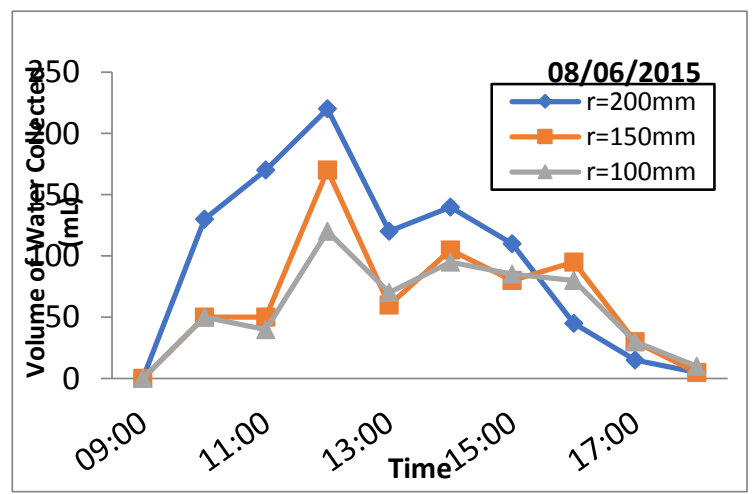

Figure 13 The hourly amount of water distilled from the half-TSS models with constant tray dimensions 


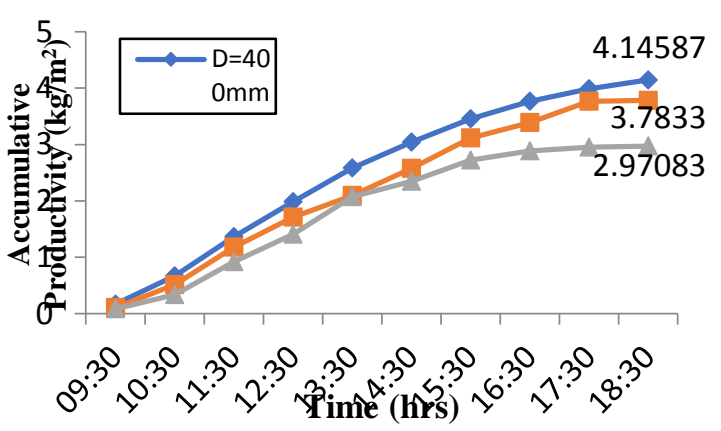

Figure 14Accumulative productivity of full-TSS models with constant tray dimensions

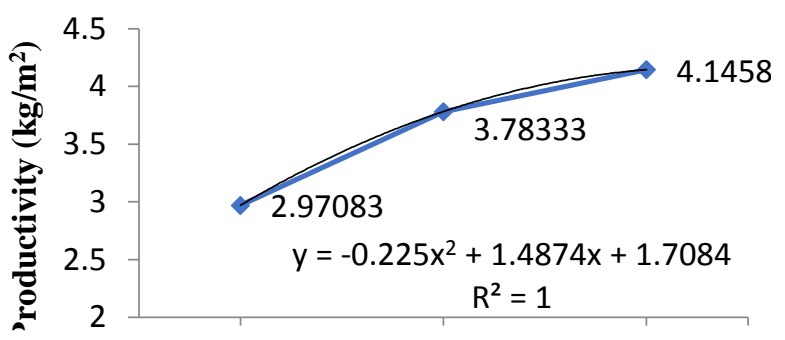

Volume of air $\left(\mathrm{m}^{3}\right)$

$\leadsto$ Productivity $(\mathrm{kg} / \mathrm{m} 2)$

Figure 15 Accumulative productivity of full-TSS models with constant tray dimensions with respect to volume of humid air

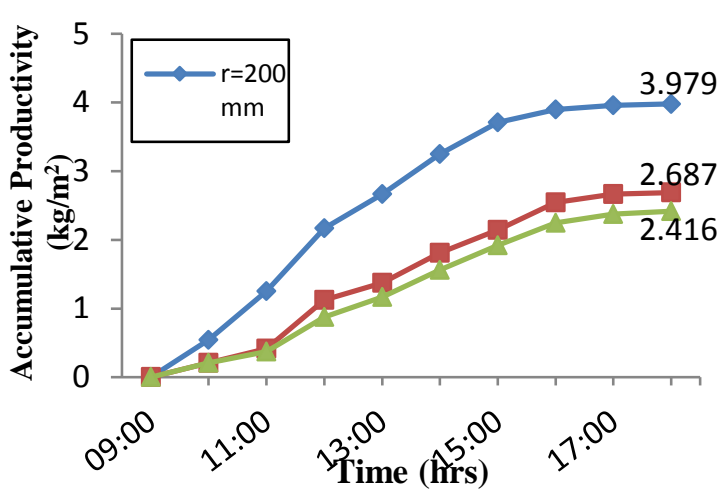

Figure 16 Accumulative productivity of half-TSS models with constant tray dimensions

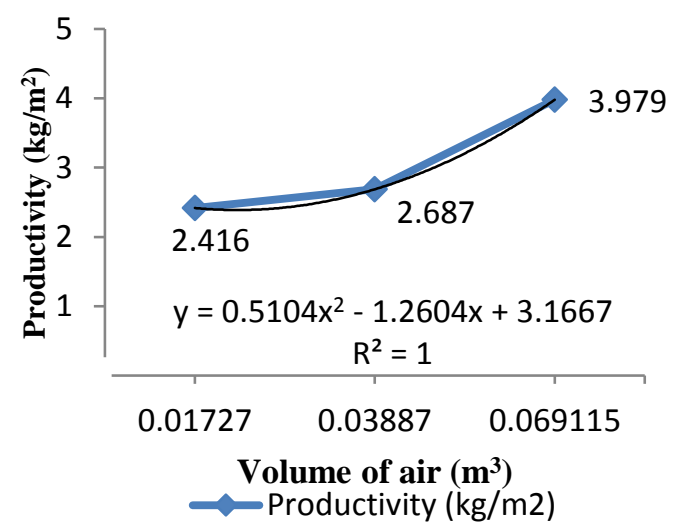

Figure 17 Accumulative productivity of half-TSS models with constant tray dimensions with respect to volume of humid air

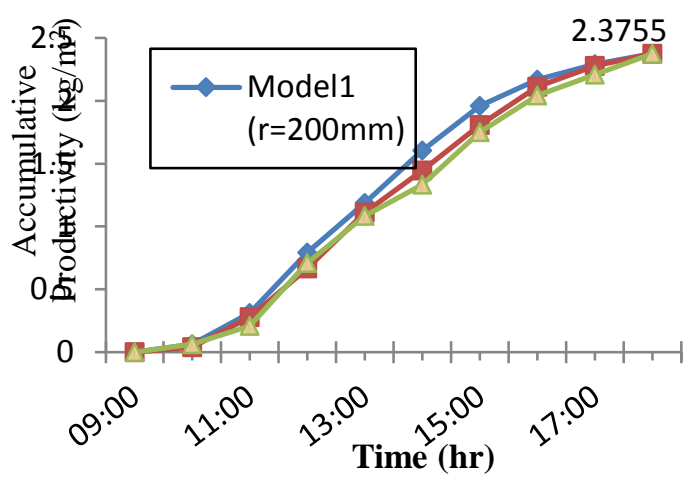

Figure 18Accumulative productivity of half-TSS models with variable tray dimensions

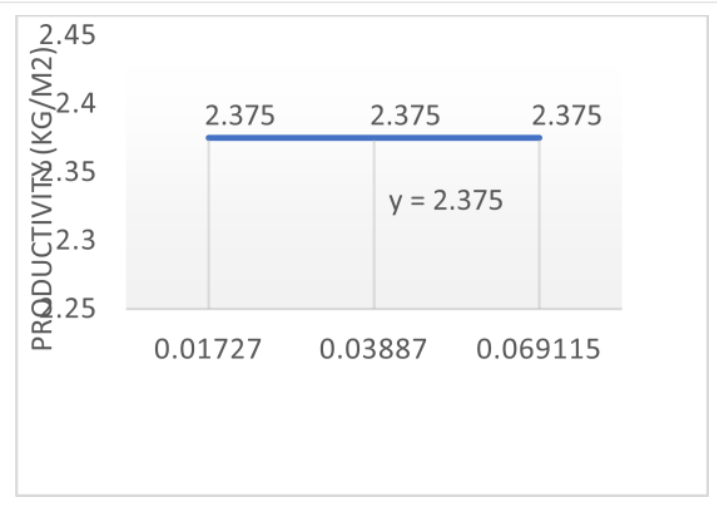

Fig. 19 Accumulative productivity of half-TSS models with variahle trav dimensions with 
Measurements on the weather conditions for solar intensity, ambient temperature and wind speed were taken in 14/05/2014 for the full-TSS models, $02 / 06 / 2015$ and 08/06/2015 for the half-TSS models with constant and variable tray dimensions respectively to study the effect of weather conditions and their impact on the productivity. Starting with the full-TSS models, figure (11) shows a comparison between the three full-TSS models and the volume of water collected from them during the day 14/05/2014 from 09:00 am to 06:00 pm. The figure illustrates that the maximum water productivity accumulated for the three models was at 12:00 pm and the systems nearly stopped productivity after sundown. It can be clearly seen that the model with the largest diameter of 400 $\mathrm{mm}$ has the largest water distilled productivity of 167 $\mathrm{mL}$ at 11:00 am, the models with 300 and $200 \mathrm{~mm}$ diameter come next with the same productivity rate of $160 \mathrm{~mL}$ at 12:00 pm. The main trend of the line graph shows a huge increase of water distilled for the three models from 09:00 am until afternoon, then a steep decrease for all models with slight fluctuations in productivities for the models 300 and $200 \mathrm{~mm}$ diameter until the sunset. Figure (12) shows a comparison between the volume of water collected for the three half-TSS models with variable tray dimensions on 02/06/2015 from 09:00 am to 06:00 $\mathrm{pm}$. The figure shows that the top water productivity accumulated for the three models was at 12:00 pm and 01:00 pm then a fluctuated decrease of the water productivity occurred during the day till 06:00 pm. The highest productivity comes from the model with the largest radius of $r=200 \mathrm{~mm}$ with distilled water of 230 $\mathrm{mL}$ at 12:00 pm. At 01:00 pm the model of $\mathrm{r}=150 \mathrm{~mm}$ records the higher productivity of $160 \mathrm{~mL}$, then 120 $\mathrm{mL}$ for the smallest model of $\mathrm{r}=100 \mathrm{~mm}$ at $12: 00 \mathrm{pm}$. Figure (13) shows a comparison for models with halftubes and constant tray dimensions that were conducted by the test on $08 / 06 / 2015$. It is obvious that the highest productivities of all the models were at 12:00 pm while the volume of water collected for all models were at their highest rates as shown in figure with values of 220, 170 and $120 \mathrm{~mL}$ for models with radii of 200,150 and $100 \mathrm{~mm}$ respectively. A fluctuation in distilled water productivity recorded after 12:00 pm till they reached zero water production at 18:00 pm for all models due to weather conditions.

The accumulative production rates of full-TSS models distilled water are obtained during the day for each model and presented per unit area. Figure (14) shows that the maximum amount of production rate occurred between the three experimental models of the full-TSS. The accumulative productivity per day was highest when the full-TSS with constant tray dimensions was used with $3.9125 \mathrm{~kg} / \mathrm{m}^{2}$ for the diameter of $400 \mathrm{~mm}$, followed by $3.7833 \mathrm{~kg} / \mathrm{m}^{2}$ for the middle-sized model with diameter of $300 \mathrm{~mm}$, and the lowest accumulative productivity was $2.97 \mathrm{~kg} / \mathrm{m}^{2}$ for the lowest TSS diameter of $200 \mathrm{~mm}$. Figure (15) shows the accumulative productivity of full TSS models with constant tray dimensions with respect to volume of humid air. The experimental data shows the productivity as a function of the volume of humid air.

(4.1) where $(y)$ is the productivity $\left(\mathrm{kg} / \mathrm{m}^{2}\right.$ day) and $(x)$ is the humid air volume $\left(\mathrm{m}^{3}\right)$.

The production rate of half-TSS with constant tray dimensions took the second rank of the daily accumulative production of distilled water with respect to humid air volume, with $3.979 \mathrm{~kg} / \mathrm{m} 2$ for a $200 \mathrm{~mm}$ radius, $2.687 \mathrm{~kg} / \mathrm{m} 2$ for a $150 \mathrm{~mm}$ radius and $2.416 \mathrm{~kg} / \mathrm{m} 2$ for a $100 \mathrm{~mm}$ radius per day as shown in figure (16). Figure (17) shows the productivity as a function of the volume of humid air.

$$
y=0.5104 x^{2}-1.2604 x+3.1667
$$

where $(y)$ is the productivity $\left(\mathrm{kg} / \mathrm{m}^{2}\right.$ day $)$ and $(x)$ is the volume of humid air $\left(\mathrm{m}^{3}\right)$.

The lowest production rate per unit area were taken from the half-TSS models with variable tray dimensions. It was noticed that at the end of the day the accumulative production of distilled water was equal for all three models with $2.375 \mathrm{~kg} / \mathrm{m}^{3}$ for the 200,150 and $100 \mathrm{~mm}$ radii with respect to humid air volume as shown in figure (18). A constant productivity shown in figure (19) as a function of the volume of humid air.

$$
\mathrm{y}=2.375
$$

where $(\mathrm{y})$ is the productivity $\left(\mathrm{kg} / \mathrm{m}^{2}\right.$ day).

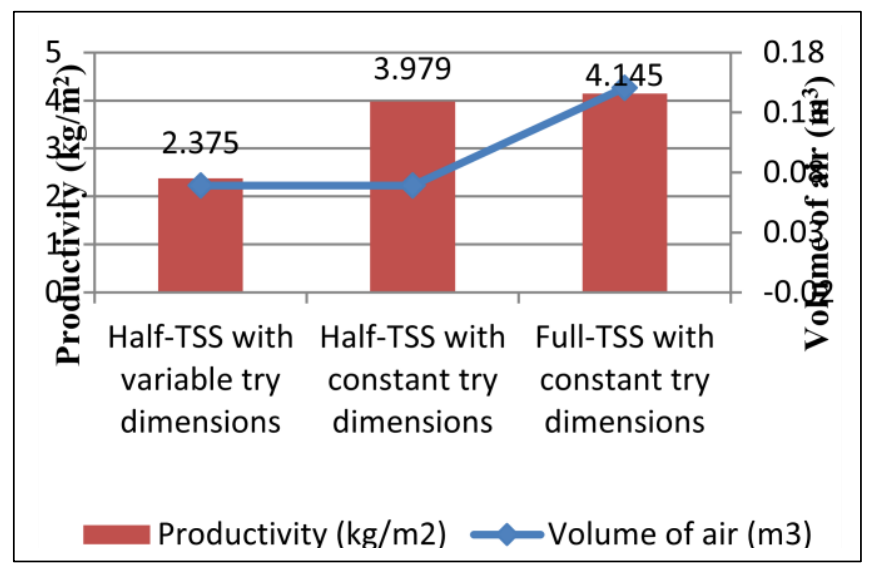

Fig. 20 Comparison between three TSS models for the three experiments with the same $200 \mathrm{~mm}$ radius $V$ s the

\section{Conclusions}

In the present thesis, work modeling of evaporation and condensation process is done for different diameters of condensing covers and different tray dimensions to optimize the mass yield to improve the performance of distillation unit under normal weather conditions. The performance of solar stills is evaluated by varying the temperature at the bottom of the solar still from $40{ }^{\circ} \mathrm{C}-60{ }^{\circ} \mathrm{C}$ at radii of 100,150 and $200 \mathrm{~mm}$. The behavior of phase change and temperature distribution is observed due to evaporation. The temperature of water obtained and mass yield are compared. By plotting the curves of mass of water produced, convective and evaporative heat transfer coefficients are optimized with regard to which condensing cover attained the best performance. Based on the results of the present 
work a comparison between the three TSS models for the three experiments on the same $200 \mathrm{~mm}$ radius were done as shown in figure (20), to reveal the variation of distilled water productivity throughout the day with respect to the volume of humid air. As a result of the comparison, the maximum productivity was achieved from the full-TSS model with constant tray dimensions with the value of $4.145 \mathrm{~kg} / \mathrm{m}^{2}$ day, followed by the half TSS model with constant tray dimensions by $3.979 \mathrm{~kg} / \mathrm{m}^{2}$ day with a slight productivity difference of $4 \%$ between the two models. The least productivity value per day was extracted from the half TSS model with variable tray dimensions with a productivity difference of $40 \%$ less than the same model with constant tray dimensions, and with a difference of $42.7 \%$ in lower productivity than the full TSS with constant try dimensions. The difference in distilled water production between the full- and half-TSS models with constant tray dimensions amounted to $0.166 \mathrm{~kg} / \mathrm{m}^{2}$. It is obvious from the economical point of view, that the half-TSS with constant tray dimensions is the best selection for the maximum pure water productivity as it is exactly $50 \%$ off glass/plastic cover price than the full glass/plastic model with only a $4 \%$ difference in productivity.

\section{References}

[1] Human Development Report 2006. UNDP, 2006 Coping with water scarcity. Challenge of the twenty-first century. UNWater, FAO, 2007

[2] B.A. Jubran1, M.I. Ahmed, A.F. Ismail, Y.A. Abakar. Numerical modelling of a multistage solar Still, Energy Conversion \& Management 41 (2000) 1107-1121

[3]

K.Sampathkumar,T.V.Arjunan,P.Pitcha

ndi,P.Senthilkumar,Activesolardistillation-A detailed review, Renew. Sustainable Energy

Rev. 14 (2010) 1503-1526

[4] G.N. Tiwari and A. Tiwari, Solar Distillation Practice for Water Desalination Systems, Anamaya, New Delhi, 2007.

[5] H.P. Garg and H.S. Mann, Effect of climatic, operational and design parameters on the year round of single-sloped and doublesloped solar still under Indian arid zone conditions, Solar Energy, 18 (1976) 159-163.

[6] J.A. Eibling, S.G. Talbert and G.O.G. Lof, Solar stills for community use-digest of technology, Solar Energy, 13 (1971) 263-276 